\title{
Social capital, pathway to care and duration of untreated psychosis: Findings from a low- and middle-income country context
}

\author{
J K Burns, J B Kirkbride \\ Department of Psychiatry, Nelson R Mandela School of Medicine, University of KwaZulu-Natal, Durban \\ J K Burns, MB ChB, MSc, FCPsych (SA), PhD
}

Department of Psychiatry, University of Cambridge, United Kingdom

J B Kirkbride, $\mathrm{PhD}$

Corresponding author: J K Burns (burns@ukzn.ac.za)

\begin{abstract}
Background. Socio-environmental factors are associated with an increased incidence of psychosis and may affect the pathway to care in first-episode psychosis (FEP).

Objective. To determine the relationship between individual- and neighbourhood-level socio-environmental factors (household income and rated measures of neighbourhood social capital) and duration of untreated psychosis (DUP) in South Africa.

Methods. We obtained data regarding sociodemographics, evolution of symptoms and pathway to care from interviews with 54 consecutively admitted FEP patients at Town Hill Hospital. Caregivers and clinical notes were also consulted. A population-based survey of social capital was conducted in the residential neighbourhood of each patient at onset. Cox regression analyses were used to test whether socioeconomic factors and overall neighbourhood social capital scores and sub-scores were associated with DUP.

Results. After controlling for age at onset, gender and income, a shorter DUP was independently associated with police involvement in pathways to care, while non-black ethnicity and greater levels of total social capital were associated with a longer DUP. Community participation, neighbourhood connectedness, and trust and safety were specifically associated with a longer DUP.

Conclusions. Individual factors including greater age at onset and police involvement in the care pathway were significantly associated with shorter DUP in this middle-income setting. Paradoxically, aspects of social capital pertaining to greater community involvement were associated with delays in pathways to appropriate care. It is possible that community members opted to care for individuals with early psychosis longer before sending them to formal health services. This is especially likely in contexts where mental health services are scarce and inaccessible, which has important implications for mental health education campaigns.
\end{abstract}


Socio-environmental factors, measured at both the individual (e.g. unemployment and low socioeconomic status ${ }^{1-3}$ ) and neighbourhood level (e.g. urbanicity, ethnic density, deprivation and income inequality $\left.{ }^{4-8}\right)$, are associated with an increased incidence of psychosis. Such factors may also affect pathways to care and the duration of untreated psychosis (DUP) in firstepisode psychosis (FEP) within middle-income countries such as South Africa. Longer DUP is known to be predictive of poorer short- and long-term outcome in high- as well as low- and middleincome country (LAMIC) contexts. ${ }^{9-11}$ DUP, the period between onset of psychotic symptoms and commencement of treatment, often has a markedly skewed distribution, with most individuals presenting soon after the onset of psychosis (within 10 weeks ${ }^{12}$ ), and a few presenting many years later. Since this delay has negative implications for course and outcome, it is important to identify factors that may contribute to long DUP, ${ }^{13}$ as well as those which might be protective against longer DUP.

One feature of the social environment that may be protective against serious mental disorders is social capital. Referring to the ability of individuals to draw on collective group-level resources, social capital is a concept that emerged from the social, economic and political sciences, ${ }^{14}$ but in recent years has also entered the health domain as a possible explanatory factor for variations in health, and as a potential target for interventions. ${ }^{15}$ Social capital describes aspects of social networks, relations, trust and power, and incorporates the following aspects of social life: ${ }^{14}$ the extent and intensity of engagement and participation in social activities, community structures and civic life; the extent and intensity of social networks, relationships and support; local civic identity and sense of belonging, solidarity and equality with other members; reciprocity and norms of co-operation and a sense of obligation or responsibility to help others; shared values with the community; and trust in the community. It can be studied as a property of individuals or as a property of groups (ecological). The latter is most commonly measured by aggregating individual social capital at a particular spatial level, such as a city neighbourhood. ${ }^{15}$

There is a growing literature on the relationships between social capital and mental health. ${ }^{15-19}$ It has been hypothesised that social capital reduces negative life events and long-term difficulties and protects against mental ill-health. ${ }^{20}$ Mental healthcare service use and hospitalisation have been measured in relation to neighbourhood levels of social capital. Strong neighbourhood trust and social cohesion were found to reduce mental healthcare service use in children from socioeconomically deprived neighbourhoods in Maastricht in The Netherlands, ${ }^{19}$ while low levels of linking social capital was associated with increased hospitalisation due to psychosis in the Swedish adult population, even after adjustment for neighbourhood deprivation. ${ }^{21}$

Whether aspects of the social environment, including social capital, are associated with DUP and pathways to care remains unclear, particularly within LAMIC settings, but this potentially has important implications for health service provision. Compton and colleagues ${ }^{22}$ examined socioeconomic predictors of DUP in a sample of AfricanAmerican FEP patients and found that those without health insurance, with financial problems or barriers to seeking help, had a significantly longer DUP. In a review of published studies of DUP from LAMICs, Large and colleagues ${ }^{23}$ found an inverse relationship between gross domestic product and DUP. Therefore, at an ecological level, lower income correlates with a longer DUP. Finally, in the only study to have investigated the possible association between neighbourhood social factors and DUP, Kirkbride and colleagues ${ }^{24}$ reported no relationship between neighbourhood-level factors and DUP.

We sought to investigate the relationship between DUP and individual and neighbourhood-level socio-environmental factors, including household income and independent measures of neighbourhood social capital, in a South African context. Specifically, we sought to test the hypothesis that longer DUP would independently be associated with socio-environmental difficulties (including urban status, limited schooling, unemployment, single status, household overcrowding, low household income and low neighbourhood social capital).

\section{Methods}

Over a 12-month period (1 July 2008 - 1 July 2009), all patients admitted with FEP to Town Hill Hospital, KwaZulu-Natal, were considered for inclusion in the study. Inclusion criteria included: a clinical Diagnostic and Statistical Manual of Mental Disorders (fourth edition, text revision) (DSM-IV-TR) diagnosis of schizophreniform disorder, schizophrenia or schizo-affective disorder; and confirmation of first-episode status through review of clinical records and consultation with the primary caregiver. Exclusion criteria were: age-at-contact $\leq 16$ years or $\geq 45$ years; intellectual disability; confirmed history or evidence of epilepsy on electro-encephalography; evidence of psychotic illness precipitated by a general medical condition; and clear clinical evidence of substance-intoxication or withdrawal (or a definite history of substance use within the week prior to admission). Participants provided written informed consent after the study was explained in their first language. The study was approved by the Biomedical Research Ethics Committee of the University of KwaZulu-Natal.

\section{Sociodemographic and clinical ratings}

Patients were interviewed on admission by one of two psychiatrists and rated with the positive and negative syndrome scale (PANSS) ${ }^{25}$ as well as the Calgary Depression Scale for Schizophrenia (CDSS). ${ }^{26}$ Both investigators received prior training in the administration of these instruments and inter-rater reliability was satisfactory $(r=0.88$ and 0.84 , respectively). Demographic and socio-environmental data were obtained from interviews with the patient and an adult family member living in the home (for verification), as well as from clinical notes. Specifically, socio-environmental data included: urban v. rural status; years of schooling; marital status (single/separated v. married/ partner); employment status; total household income; number of people living in the home; number of rooms in the house; experience of traumatic events, including experience of racism or discrimination, a history of physical or sexual assault, witnessing beatings, other acts of violence or killings, parental death or the loss of children. We also collected data on the pathway to care (referral source, any police involvement), a family history of mental illness or previous treatment for a psychiatric disorder from a psychiatrist, other qualified medical 
practitioner or a traditional healer. With the exception of variables pertaining to household size (continuous integers), these variables were dichotomised as binary (i.e. yes/no) variables. Total household income was dichotomised into two categories: $\geq$ R2 000 (\$300) per month and $<$ R2 000 per month. This figure was arrived at as an estimate of mean household income in this population based on previous surveys in patients at the hospital. ${ }^{8}$ Information relating to the onset of psychosis was obtained from interviews with the patient and relatives, and from clinical notes.

\section{Social capital measures}

The Social Capital Questionnaire (SCQ) developed and validated by Bullen and Onyx $x^{27}$ in Australia, is suitable for developing country contexts ${ }^{27}$ and was therefore used in this study. The SCQ comprises 36 questions relating to aspects of the respondents' residential (31 items) and work (5 items) environment, with four possible responses to each item scored from 1 ('no, not at all') to 4 ('yes, frequently'). Because not all respondents were employed, we excluded the five workrelated items to give an overall maximum total social capital score of 124. Seven sub-scores of social capital can be derived by summing previously validated questions focused on a specific theme. ${ }^{27}$ These include: community participation; proactivity in a social context; feelings of trust and safety; neighbourhood connections; family and friends connections; tolerance of diversity; and value of life. Neighbourhood-level total social capital and sub-scores were derived by calculating mean scores from all respondents surveyed. These scores were entered into analyses as $z$-standardised variables to have a mean of 0 and standard deviation (SD) of \pm 1 .

\section{Neighbourhood survey strategy}

For each patient, a survey of 15 households was conducted in their immediate neighbourhood at first contact with services. A fieldworker travelled to the address and began the survey at the first house to the left of the patient's address. Thereafter, the next house to the left was surveyed and so forth. If no-one was home, the fieldworker selected the next house to the left until 15 houses had been surveyed. At each house, an adult resident was asked to complete the questionnaire. No contact was made with residents at the patient's address. Furthermore, no reference to the patient was made when interacting with his/ her neighbours. In this manner, the survey yielded independent observations of social capital in the neighbourhood of each patient.

\section{Definition of DUP}

DUP was defined as the period in weeks between the first appearance of positive psychotic symptoms and initiation of treatment in hospital. Consistent with previous studies, ${ }^{13}$ onset of psychosis was defined as the presence of one or more of the following positive symptoms for at least one week: hallucinations; delusions; thought disorder; and disorganised or bizarre behaviour with a marked deterioration in function. Information concerning the onset of symptoms was obtained in detailed interviews conducted with the participants and their primary caregivers.

\section{Statistical analysis}

Missing data were handled through multiple imputation (MI), which allows plausible values for missing data to be estimated based on known values of other variables in the dataset. ${ }^{28}$ Unlike other approaches, such as list-wise deletion, mean substitution or single imputation, multiple imputation (MI) is underpinned by Bayesian theory such that sampling from the posterior predictive distribution of possible values which missing data could take, given the observed data, yields a set of plausible values that the missing data could take. Retaining estimates from several successive imputations, or $M$ (range typically between 5 and 20), allows standard regression-based models to be fitted for each imputation. Parameter estimates and respective standard errors are then combined over $M$ imputations using Rubin's rules to account for within- and between-imputation variance to give an unbiased parameter estimate for each variable included in the final model. ${ }^{29}$

We fitted MI models using the MI suite of commands available in Stata software (version 11.2). In general, the proportion of missing data was relatively small (5\%) in relation to the number of subjects and variables available for analysis. Variables with missing data were estimated under MI by fitting appropriate imputation models (linear regression for continuous variables, logit models and their extensions for binary, nominal and ordinal categorical data), with all variables with complete data used to estimate missing values. These variables included the outcome of interest, DUP, as well as age-at-onset, gender, ethnicity, relationship status, rural/urban residence, employment status and income. All imputed data were checked for logical values. Social capital scores and sub-scores, which were missing for four subjects and therefore imputed scores (non-standardised) were obtained using the methods described above. Following MI, scores were $z$-standardised.

We then used Cox regression, appropriate for the analysis of survival data such as DUP to test for possible associations with individual and neighbourhood-level social factors. DUP was entered into the model in days. Date of birth, onset and assessment were entered as origin, entry and exit points of the survival analysis, respectively. Model-building under MI is an area of ongoing research because it is not possible to perform likelihood-based tests of model fit on multiply imputed data. ${ }^{29}$ We therefore followed the guidelines of Wood et al. ${ }^{29}$ and, prior to fitting the final model in an MI framework, we extracted each observation on $N$ subjects from each of $M$ imputations to produce a 'stacked' dataset of the multiply-imputed data. This yields a dataset of effectively $N M$ observations which can be used to fit and build standard Cox regression models based on maximum likelihood comparisons such as the likelihood ratio test (LRT). However, because the dataset was now $N M$ observations in length (and not $N$ observation in length) standard errors needed to be adjusted, typically by weighting them according to the proportion of missing data (5\%) in the original dataset prior to MI. We employed a forward-fitting stepwise modelling strategy to estimate the best model and set an initial LRT threshold of $p=0.099$ because of our relatively small sample size. Age-at-onset and gender were treated as a priori confounders in the model. The final model obtained in this environment was then estimated under the MI framework to provide precise parameter estimates for each relevant predictor of DUP.

The assumption of proportional hazards was found not to be invalidated in the final models ( $p$-values $>0.20$ ). Sub-scores of social capital were entered into the final model to determine whether any particular components of this construct were associated with DUP, having accounted for a range of other predictors. Hazard ratios (HRs) 
$>1.0$ represent the increased risk of contact with services, and hence indicate shorter DUPs.

\section{Results \\ Patient characteristics}

Sixty-one patients were identified from the case-ascertainment procedure; 54 agreed to participate (88.5\%). The age-and-gender distribution of subjects was similar to other first-episode samples with age at onset skewed towards younger ages in men (median 21.5 years; interquartile range (IQR) 19 - 26) and a later median age at onset in women (26.5 years; IQR 20.5 - 38.5). The sample was predominantly male (70\%), of Zulu (black) ethnicity (85\%) and of single/separated marital status (85\%). Most participants resided in urban areas (62\%) and just over half were unemployed (51\%). Mean household income was R2 560 (\$365) per month, while most participants lived in houses with fewer than 5 rooms (52\%) with $\geq 5$ individuals living in the home (59\%). Seventy-nine per cent were referred to mental healthcare services by family members rather than by general practitioners; and the majority of patients (81\%) were admitted involuntarily under the Mental Health Care Act of 2002. Police involvement in the admission occurred in 44\% of cases. Thirty-eight per cent had a positive psychiatric history, 35\% used cannabis regularly, and HIV-seropositivity was detected in $22 \%$ of those who were tested during their admission. There was no significant difference in terms of demographics between the study sample and the 7 patients who declined study participation.

\section{FEP clinical features}

The median DUP was 6 weeks (IQR 3 - 28; mean 35.08 weeks; $\mathrm{SD} \pm 62.01$; range 1 - 260) (Fig. 1). We observed a statistically significant difference (Wilcoxon rank sum test $z=-2.7 ; p=0.01$ ) in DUP between the black (median 4 weeks; IQR 3 - 10) and non-black (median 91 weeks; IQR 32.5 - 150) ethnic groups. The mean PANSSpositive score was 15.8 ( $\mathrm{SD} \pm 6.5$; range 7 - 32), mean PANSS-negative score was 13.15 (SD \pm 5.7 ; range 7 - 30) and mean PANSS general score was 24.9 (SD \pm 9.5 ; range 16 - 56). The mean CDSS score was 6.08 (SD 4.83 ; range $0-21$ ).

\section{Sociodemographic factors, social capital and DUP}

The Cox regression analysis, following MI, revealed that a model with ethnicity and police involvement in the pathway to care provided the best fit to the DUP data, having controlled for age at onset, gender and income (Adjustment 1, Table 1). Of these potential confounders, only an increased age at onset was significantly associated with shorter DUP (HR 2.47; 95\% CI 1.17 - 4.85). People of non-black ethnicity had a significantly longer DUP than people of black (Zulu) ethnicity (HR 0.19; 95\% CI 0.04 - 0.81), after adjustment for confounders, including police involvement in the referral pathway, which was associated with a shorter DUP (HR 5.66; 95\% CI 1.20 - 26.80). When total social capital was added to this model, we observed a trend towards statistical significance ( $p=0.07$ ), indicating that greater neighbourhood social capital may have been associated with a longer DUP in this sample (HR per standard deviation change $0.40 ; 95 \%$ CI 0.15 - 1.08).

To inspect this further, we entered the subdomains of social capital separately into the final model in place of our overall social capital variable (Table 2). This revealed that two domains were significantly

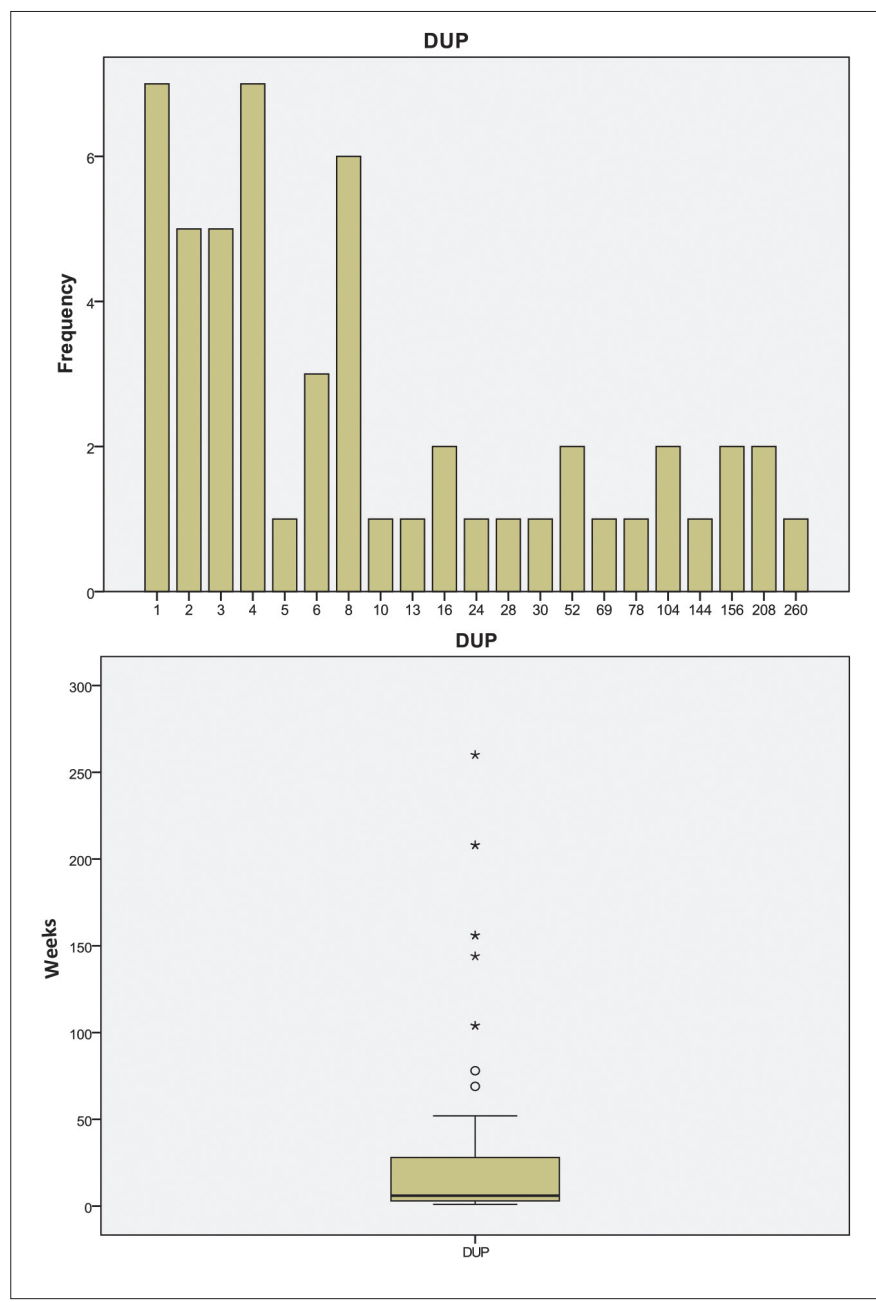

Fig. 1. Skewed distribution of DUP.

associated with a longer DUP: community participation (HR 0.46; 95\% CI $0.22-0.93 ; p=0.03$ ) and neighbourhood connectedness (HR $0.19 ; 95 \%$ CI $0.04-0.78 ; p=0.02$ ), while a third, 'feelings of trust and safety', approached conventional statistical significance (HR 0.48; 95\% CI 0.23 - $1.02 ; p=0.06$ ).

Because presentation with a more negative symptomatology has previously been associated with a longer DUP, ${ }^{30}$ we went on to consider whether this confounded our model (Adjustment 2, Table 1). In univariate analysis, more PANSS-negative symptoms were strongly associated with a longer DUP (HR 0.87; 95\% CI 0.81 - 0.94), but this did not persist in our fully adjusted model (HR 0.96; 95\% CI 0.86 1.06; $p=0.39$ ). Negative symptoms had a weak confounding effect on other associations, which remained broadly significant.

\section{Discussion}

We sought to investigate associations between demographic and socio-environmental variables (including household income and social capital) and DUP. As DUP has been shown to correlate well with short- and long-term outcome, it is important to clarify the possible effect that demographic and socio-environmental factors may have on this prognostic indicator. This is particularly important, we argue, in a developing country context where socioeconomic 
Table 1. Survival analysis using Cox regression to investigate sociodemographic and socio-environmental factors associated with DUP ${ }^{\star}$

\begin{tabular}{|c|c|c|c|c|c|}
\hline $\begin{array}{l}\text { Risk factor } \\
(N=54)\end{array}$ & $\begin{array}{l}\text { Unadjusted HR }(95 \% \\
\mathrm{CI})\end{array}$ & $\begin{array}{l}\text { First adjustment }^{\dagger} \\
\text { HR }(95 \% \mathrm{CI})\end{array}$ & $\begin{array}{l}\text { Wald } \\
p \text {-value }\end{array}$ & $\begin{array}{l}\text { Second adjustment }{ }^{\dagger} \\
\text { HR }(95 \% \mathrm{CI})\end{array}$ & $\begin{array}{l}\text { Wald } \\
p \text {-value }\end{array}$ \\
\hline Age at onset (per year) & $1.84(1.30-2.62)$ & $2.47(1.19-5.14)$ & 0.02 & $2.14(0.98-4.69)$ & 0.06 \\
\hline Gender & $1.06(0.43-2.58)$ & $0.27(0.05-1.42)$ & 0.13 & $0.32(0.05-1.86)$ & 0.20 \\
\hline \multicolumn{6}{|l|}{ Income } \\
\hline$<\mathrm{R} 2000$ (v. > R2 000) & $0.14(0.03-0.56)$ & $1.41(0.08-17.90)$ & 0.80 & $1.03(0.06-17.1)$ & 0.99 \\
\hline No info (v. >R2 000) & $1.26(0.22-7.05)$ & $110.9(16-7765.3)$ & 0.03 & $61.3(0.88-4281.0)$ & 0.06 \\
\hline Ethnicity (non-black v. black) & $0.21(0.07-0.61)$ & $0.19(0.04-0.81)$ & 0.03 & $0.22(0.0-0.95)$ & 0.04 \\
\hline $\begin{array}{l}\text { Police involvement in pathway to care } \\
\text { (yes v. no) }\end{array}$ & $2.30(1.02-5.22)$ & $5.66(1.20-26.80)$ & 0.03 & $4.76(0.99-22.9)$ & 0.05 \\
\hline Social capital (1 SD increase) & $1.17(0.74-1.83)$ & $0.40(0.15-1.08)$ & 0.07 & $0.36(0.13-1.01)$ & 0.05 \\
\hline Negative symptoms (PANSS) & $0.87(0.81-0.94)$ & - & & $0.96(0.86-1.06)$ & 0.39 \\
\hline
\end{tabular}

Table 2. Survival analysis with subdomains of social capital fitted in final model

\begin{tabular}{|c|c|c|c|}
\hline Subdomain of social capital ${ }^{\star}$ & $\begin{array}{l}\text { Unadjusted } \mathrm{HR}^{\dagger} \\
(95 \% \mathrm{CI})\end{array}$ & $\begin{array}{l}\text { Adjusted } \mathrm{HR}^{\dagger, \neq} \\
(95 \% \mathrm{CI})\end{array}$ & $\begin{array}{l}\text { Wald } p \text {-value } \\
\text { (adjusted model) }\end{array}$ \\
\hline Community participation & $0.69(0.46-1.02)$ & $0.46(0.22-0.93)$ & 0.03 \\
\hline Social proactivity & $1.30(0.87-1.96)$ & $1.10(0.51-2.37)$ & 0.80 \\
\hline Feelings of trust and safety & $1.10(0.78-1.56)$ & $0.48(0.23-1.02)$ & 0.06 \\
\hline Neighbourhood connectedness & $0.53(0.32-0.86)$ & $0.19(0.04-0.78)$ & 0.02 \\
\hline Family and friends connections & $0.88(0.57-1.36)$ & $0.71(0.34-1.48)$ & 0.36 \\
\hline Tolerance of diversity & $1.08(0.67-1.74)$ & $1.27(0.59-2.75)$ & 0.55 \\
\hline Value of life & $0.86(0.53-1.39)$ & $1.14(0.52-2.50)$ & 0.74 \\
\hline \multicolumn{4}{|c|}{$\begin{array}{l}\mathrm{HR}=\text { hazard ratio; } \mathrm{CI}=\text { confidence interval; } \mathrm{MI}=\text { multiple imputation. } \\
{ }^{*} \mathrm{HR} \text { is associated with } 1 \text { standard deviation change in DUP, where a HR }<1 \text { indicates longer DUP. } \\
{ }^{+} \text {Fitted following } \mathrm{MI} \text { to account for missing data. }\end{array}$} \\
\hline
\end{tabular}

conditions are generally poor for the majority of individuals treated within the public mental health system. Here, we observed that having controlled for important confounders, including income, a shorter DUP was associated with police involvement in the pathway to care. Our data suggested that people from non-black (white and Indian) ethnic groups in our sample experienced significantly longer DUP than their black counterparts. Interestingly, the relationship between social capital and DUP was in the opposite direction to that which we hypothesised; people in neighbourhoods where there appeared to be greater social capital had a significantly longer DUP.

The demographics of our sample generally match those of the region's general population. The prevalence of HIV $(22 \%)$ is only marginally higher than that of the general population (18\%). However, the proportion of patients who were single or separated (85\%) was much higher than in the general population (55\%). This is consistent with other first-episode samples. ${ }^{31-34}$ Mean household income (R2 560 (\$365) per month) was less than half that of the general population (R5 360 (\$777) per month), consistent with previous findings. ${ }^{32-34}$

\section{Ethnicity and gender}

Unexpectedly, non-black ethnicity was associated with substantially longer DUP in our sample. In the South African context, one may have expected the traditionally less-privileged black groups to have had poorer access to healthcare and consequently a less favourable developmental history - thereby favouring a longer DUP. Inspection of the basic, descriptive data by ethnicity suggested, however, that the distribution of DUP in the black group resembled the DUP distribution in other settings, ${ }^{13}$ predominantly based on white European samples. In our South African context, therefore, we observed unusually long DUP for non-black groups. This was not explained by other factors included in our models, such as age at onset, gender, a more negative symptomatology or police involvement in the pathway to care.

There was no evidence of any statistically significant gender differences in DUP at odds with studies which have observed both a shorter ${ }^{35-37}$ and longer DUP for women..$^{13,38}$ Most evidence suggests a more favourable clinical presentation of FEP, as well as a better 
outcome, in women. ${ }^{38,39}$ This may be related to the protective effects of oestrogen on central dopamine $\mathrm{D} 2$ receptors. ${ }^{40}$

\section{Household income and pathway to care}

DUP was unrelated to household income, although income data were unobtainable for a large proportion of our sample, who had much shorter DUPs. Missing data for this group were not subject to the MI procedures above, because we felt that there were likely to be strong reasons why absence violated the central assumption underpinning MI - that data are missing at random (MAR) (i.e. assumed to be explained entirely by the observed data). Rather, income data may not have been reported for systematic, unobserved reasons (missing not at random (MNAR)), and so we included this group as a separate category in our models. Previous research has suggested that financial difficulties at the individual level ${ }^{22}$ and low income at an ecological level ${ }^{23}$ predict longer DUP. An obvious explanation is that low income and resulting poverty prevents individuals and their carers from affording costs associated with accessing mental health services. In South America, poor financial status has been correlated with poorer access to and use of mental healthcare services, ${ }^{41,42}$ and this may also be a characteristic of sub-Saharan countries.

\section{Social capital and DUP}

We found some evidence that greater levels of social capital were associated with a longer DUP, although the strength of this association only achieved statistical significance for certain subdomains, including 'community participation' and 'neighbourhood connectedness'. This association was in the opposite direction to that hypothesised in the study. We had assumed that high levels of social capital would facilitate pathway to care in FEP, as greater social capital would putatively lead to earlier interventions by neighbours 'possibly seeking greater levels of resolution of psychiatric disorder in patient-residents. ${ }^{23}$ In the Aetiology and Ethnicity in Schizophrenia and Other Psychoses (AESOP) study, Kirkbride et al. ${ }^{44}$ reported a non-linear U-shaped association between social cohesion and trust and incidence of schizophrenia, such that compared with areas in the middle of the distribution, both areas with low and high levels of social cohesion had elevated rates of disorder. They hypothesised that one explanation for the association between high social cohesion and increased incidence of FEP might be that 'psychotic individuals in these communities come to the attention of services, principally because of greater informal social control (ISC)'. In a later report they argued that if this hypothesis was true, DUP would be expected to be shorter in neighbourhoods with higher levels of social cohesion. ${ }^{24}$ However, they found no evidence for variation in DUP at the neighbourhood level. ${ }^{24}$

Our findings support an opposite explanation, at least in the South African context. We propose that a number of more direct, intermediary factors may be more important here, including the role of the family and carers, in addition to individual level predictors.

Specifically, we suggest that in communities with higher levels of social capital, people may tend to care for those with early mental illness for a longer period, before relinquishing them to hospital care. This is particularly likely within contexts characterised by a major scarcity and inaccessibility of mental healthcare resources, and may be a distinct feature of some LAMIC settings, such as South Africa. ${ }^{45}$ Where mental healthcare professionals and psychiatric clinics do not exist outside of cities and larger towns, it requires considerable effort and entails significant expense to access specialised services. In such contexts, communities strong in neighbourhood connectedness and community participation may 'manage' for longer and only resort to what is perceived as the extreme measure of involuntary admission in a distant psychiatric hospital when symptoms become socially disruptive and intolerable. The majority of patients in this study (81\%) were admitted involuntarily and this reflects common experience at this hospital. Furthermore, police involvement in the care pathway was strongly associated with a shorter DUP. It is therefore possible that within poorly-resourced contexts, high neighbourhood social capital actually delays entry to formal mental healthcare and lengthens DUP in patients with FEP. This, we argue, raises important human rights issues regarding the provision of services for those with severe mental disorders in LAMIC contexts, and lends support to Kelly's ${ }^{46}$ contention that social and economic factors such as poverty and inequality constitute a form of 'structural violence' that 'shape[s] both the landscape of risk for developing (schizophrenia) and the context in which health-care is provided'.

\section{A model of socio-environmental effect on pathway to care}

According to Wilkinson, ${ }^{47,48}$ social cohesion provides the link between income inequality and poor population health. The negative effects on health of an unequal distribution of wealth within a community are well documented. ${ }^{49-51}$ Two studies, one in

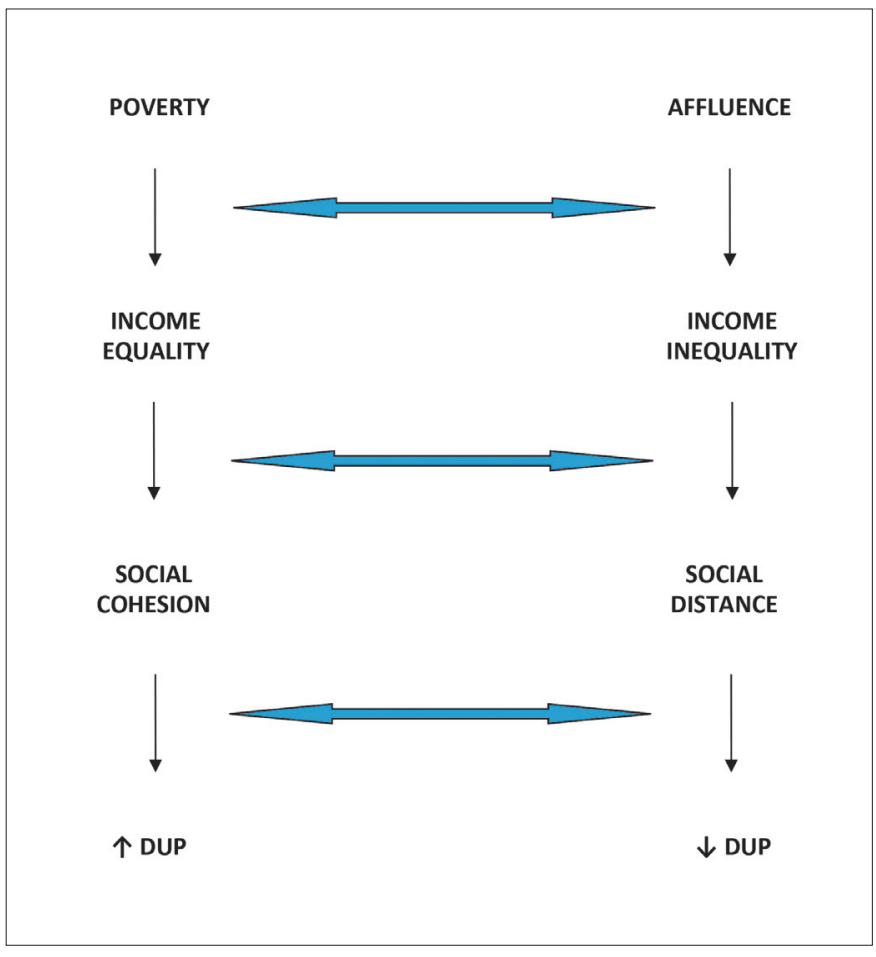

Fig. 2. The effects of poverty, income equality and social cohesion v. affluence, income inequality and social distance on the pathway to care in FEP. 
the UK and one in the same community in KwaZulu-Natal where our study was conducted, provide evidence that income inequality at an ecological level increases risk for $\mathrm{FEP}^{7,8}$ In the latter study, an inverse relationship existed between levels of poverty and levels of income inequality. This is consistent with Kuznet's ${ }^{52}$ hypothesis, which suggests that in regions with low levels of per capita income, inequality initially increases with rising income and only decreases at later stages of economic development. The relevance of this to the current findings on household income, social capital and DUP, is further discussed.

In terms of pathway to care in FEP, our results suggest a relationship between greater social cohesion and a longer DUP. Within the community in which the study was conducted, we have already demonstrated a relationship between poverty and lower income inequality. ${ }^{8}$ Therefore, it appears that, in this community, high levels of poverty and low household income are combined with relative income equality and good social cohesion to delay the pathway to care of individuals with FEP (Fig. 2). For those without access to social support at the community level, this may lead to a shorter DUP and a greater likelihood of police involvement in the care process. We can speculate that within relatively deprived communities, there is not a great deal of income disparity and, according to Wilkinson ${ }^{47,48}$ and others, ${ }^{49-51}$ this allows social cohesion to develop. Financial barriers as well as relatively high levels of community support and engagement result in individuals with early psychosis being cared for within the community for long periods. Ironically therefore, social capital may promote what community members believe is in the interests of patients, but what we know from clinical research delays medical intervention. This hypothesis requires testing in further research. If correct, then it will serve to highlight the importance of conducting mental health education programmes in local communities with a view to hastening entry to formal care for people with incipient FEP.

\section{Study limitations}

The relatively small sample size is an obvious study limitation and might have weakened the power of the statistical analysis to yield significant results in some cases. Secondly, the sample was hospital-based and therefore our results may not be generalisable to outpatient or community-based populations with FEP. Furthermore, generalisation from our results was limited by the unique social and cultural context in which the study was conducted. This is obviously of major importance when studying neighbourhood-level factors such as poverty, inequality and social capital. As with all studies of this nature, DUP was assessed retrospectively, making it possible that recall bias may have affected estimates. To limit this, DUP was assessed in consultation with both the subject and their primary caregiver. Finally, our strategy for measuring social capital and its component factors is admittedly a little unusual. In particular, each neighbourhood survey was only comprised of 15 households and we acknowledge that this is very small for a household survey. However, we argue that these 15 households together represented the immediate neighbourhood of the patient as they were the homes closest to the patient's home. We believe our social capital survey represented a measurement of the immediate and most proximate social environment experienced by the patient. This is advantageous, as a significant concern regarding the measurement of social capital in a region or community is how accurately that survey actually identifies the individual's personal neighbourhood.

MI is preferable to other means of handling missing data, including listwise deletion (where any subject with missing data would be dropped from the model) or single imputation, which may lead to biased models. MI has been shown to yield unbiased parameter estimates with robust standard errors, provided the assumption that data are MAR is satisfied. We attempted to minimise the risk of violating this assumption by including as many predictors as possible in our MI models. Our final model obtained under MI was similar when performed under standard list-wise deletion $(N=48)$, suggesting that our MI approach did not significantly alter our final conclusions. Despite these attempts to handle the $5 \%$ missing data adequately, we acknowledge that this is a sizeable proportion and may have affected our findings. Our decision not to subject missing data on household income to the MI procedures may also be open to criticism.

\section{Conclusion}

Our results suggest that both individual and neighbourhood-level socio-environmental factors affect the pathway to care in FEP. The manner in which these factors, such as poverty, inequality and social capital, have effect is likely to vary according to context. We make no claims that the model we have presented describing hypothesised relationships between poverty, inequality, social cohesion and DUP is generalisable to other contexts. Further studies in larger samples and with specific designs should be conducted in a variety of geographical and socioeconomic contexts to test our model and to clarify the ways in which it might vary in different contexts. In our context, it appears that significant work lies ahead to engage constructively with local communities on issues of mental health education, with a view to improving the pathway to care for individuals with FEP.

Acknowledgements. We acknowledge Robin Emsley for input, Khatija Jhazbhay for assistance with data collection, June-Rose Mngoma and Matilda Ngcoyi for assistance with the household survey, Nonku Mngwengwe for assistance with data entry, the National Research Foundation for funding, and participant patients and families.

\section{References}

1. Marwaha S, Johnson S. Schizophrenia and employment. Soc Psychiatry Psychiatr Epidemiol 2004;39:337-349. [http://dx.doi.org/10.1007/s00127-004-0762-4]

2. Byrne M, Agerbo E, Eaton WW, Mortensen PB. Parental socioeconomic status and risk of first admission with schizophrenia - a Danish national register based study. Soc Psychiatry Psychiatr Epidemiol 2004;39(2):87-96.

3. Cooper B. Schizophrenia, social class and immigrant status: The epidemiological evidence. Epidemiol Psichiatr Soc 2005;14:137-144. [http://dx.doi.org/10.1017/S1121189X00006382]

4. Krabbendam L, van Os J. Schizophrenia and urbanicity: A major environmental influence conditional on genetic risk. Schizophr Res 2005;31:795-799. [http://dx.do.org/10.1093/schbul/sbi060]

5. Van Os J, Krabbendam L, Myin-Germeys I, Delespaul P. The schizophrenia envirome. Curr Opin Psychiatry 2005;18:141-145.

6. Kirkbride JB, Fearon P, Morgan C, et al, Neighbourhood variation in the incidence of psychotic disorders in Southeast London. Soc Psychiatry Psychiatr Epidemiol 2007;42:438445. [http://dx.doi.org/10.1007/s00127-007-0193-0]

7. Boydell J, van Os J, McKenzie K, Murray RM. The association of inequality with the incidence of schizophrenia: an ecological study. Soc Psychiatry Psychiatr Epidemiol 2004:39:597-599. [http://dx.doi.org/10.1007/s00127-004-0789-6]

8. Burns JK, Esterhuizen T. Poverty, inequality and the treated incidence of first-episode psychosis - an ecological study from South Africa. Soc Psychiatry Psychiatr Epidemiol 2008;43:331-335. [http://dx.doi.org/10.1007/s00127-008-0308-2] 
9. Marshall M, Lewis S, Lockwood A, Drake R, Jones P, Croudace T. Association between duration of untreated psychosis and outcome in cohorts of first-episode patients: A systematic review. Arch Gen Psychiatry 2005;62:975-983. [http://dx.doi.org/10.1001/archpsyc.62.9.975]

10. Emsley R, Rabinowitz J, Medori R. Early Psychosis Global Working Group. Remission in early psychosis: rates, predictors, and clinical and functional outcome correlates. Schizophr Res 2007;89(13):129-139. [http://dx.doi.org/10.1016/j.schres.2006.09.013]

11. Farooq S, Large M, Nielssen O, Waheed W. The relationship between the duration of untreated psychosis and outcome in low-and-middle income countries: A systematic review and metaanalysis. Schizophr Res 2009;109(1-3):15-23.

12. Morgan C, Dazzan P, Morgan K, et al. First episode psychosis and ethnicity: initial findings from the AESOP study. World Psychiatry 2006;5(1):40-46.

13. Morgan C, Abdul-Al R, Lappin JM, et al. Clinical and social determinants of duration of untreated psychosis in the AESOP first-episode psychosis study. Br J Psychiatry 2006;189:446452. [http://dx.doi.org/10.1192/bjp.bp.106.021303]

14. Putnam R. Making Democracy Work: Civic Traditions in Modern Italy. Princeton, NJ: Princeton University Press, 1993.

15. Whitely R, McKenzie MD. Social capital and psychiatry: review of the literature. Harv Rev Psychiatry 2005;13(2):71-84. [http://dx.doi.org/10.1080/10673220590956474]

16. Henderson S, Whiteford H. Social capital and mental health. Lancet 2003;362:505-506. [http:// dx.doi.org/10.1016/S0140-6736(03)14150-5]

17. Almedon AM. Social capital and mental health: An interdisciplinary review of primar evidence. Soc Sci Med 2005;61:943-964. [http://dx.doi.org/10.1016/j.socscimed.2004.12.025]

18. De Silva MJ, McKenzie K, Harpham T, Huttly SRA. Social capital and mental illness: a systematic review. J Epidemiol Community Health 2005;59:619-627. [http://dx.doi. org/10.1136/jech.2004.029678]

19. van der Linden J, Drukker M, Gunther N, Feron F, van Os J. Children's mental health service use, neighbourhood socioeconomic deprivation, and social capital. Soc Psychiatry Psychiat Epidemiol 2003;38:507-514. [http://dx.doi.org/10.1007/s00127-003-0665-9]

20. Harpham T, Grant E, Thomas E. Measuring social capital within health surveys: Key issues. Health Policy Plan 2002;17(1):106-111. [http://dx.doi.org/10.1093/heapol/17.1.106]

21. Lofors J, Sundquist K. Low-linking social capital as a predictor of mental disorders: A cohort study of 4.5 million Swedes. Soc Sci Med 2007;64:21-34. [http://dx.doi.org/10.1016/j. socscimed.2006.08.024]

22. Compton MT, Ramsay CE, Shim RS, et al. Health services determinants of the duration of untreated psychosis among African-American first-episode patients. Psychiatric Serv 2009;60:1489-1494. [http://dx.doi.org/10.1176/appi.ps.60.11.1489]

23. Large M, Farooq S, Nielssen O, Slade T. Relationship between gross domestic product an duration of untreated psychosis in low- and middle-income countries. Br J Psychiatry 2008;193:272-278. [http://dx.doi.org/10.1192/bjp.bp.107.041863]

24. Kirkbride JB, Lunn DJ, Morgan C, et al. Examining evidence for neighbourhood variation in the duration of untreated psychosis. Health Place 2010;16:219-225. [http://dx.doi. org/10.1016/j.healthplace.2009.09.013]

25. Kay SR, Fitzbein A, Opler IA. The Positive and Negative Syndrome Scale (PANSS) for schizophrenia. Schizophr Bull 1987;13:261-267.

26. Addington D, Addington J, Schissel B. A depression rating scale for schizophrenics. Schizophr Res 1990;3:247-251. [http://dx.doi.org/10.1016/0920-9964(90)90005-R]

27. Bullen P, Onyx J. Measuring Social Capital in Five Communities in NSW: A Practitioner's Guide, 2nd Ed. Coogee, NSW: Management Alternatives Pty Ltd, 2005.

28. StataCorp. Stata Multiple Imputation Reference Manual: Release 11. College Station, TX StataCorp LP, 2009

29. Wood AM, White IR, Royston P. How should variable selection be performed with multiply imputed data? Stat Med 2008;27(17):3227-3246. [http://dx.doi.org/10.1002/sim.3177]

30. Larsen TK, McGlashan TH, Moe LC. First-episode schizophrenia: I. Early course parameters Schizophr Bull 1996;22(2):241-256. [http://dx.doi.org/10.1093/schbul/22.2.241]

31. MacCabe JH, Koupil I, Leon DA. Lifetime reproductive output over two generations in patients with psychosis and their unaffected siblings: the Uppsala 1915-1929 Birth Cohort Multigenerational Study. Psychol Med 2009;39:1667-1676. [http://dx.doi.org/10.1017 S0033291709005431]
32. Kendler KS, Gallagher TJ, Abelson JM, Kessler RC. Lifetime prevalence, demographic risk factors, and diagnostic validity of nonaffective psychosis as assessed in a US community sample. The National Comorbidity Survey. Arch Gen Psychiatry 1996;53:1022-1031. [http:// dx.doi.org/10.1001/archpsyc.1996.01830110060007]

33. de Souza LA, Coutinho ES. The quality of life of people with schizophrenia living in community in Rio de Janeiro, Brazil. Soc Psychiatry Psychiatr Epidemiol 2006;41:347-356.

34. Xiang YT, Ma X, Cai ZJ, et al. Prevalence and socio-demographic correlates of schizophrenia in Beijing, China. Schizophr Res 2008;102:270-277. [http://dx.doi.org/10.1016/j. schres.2008.04.009]

35. Wunderink A, Nienhuis FJ, Sytema S, Wiersma D. Treatment delay and response rate in firstepisode psychosis. Acta Psychiatr Scand 2006;113:332-339. [http://dx.doi.org/10.1111/j.16000447.2005.00685.x]

36. Thomas SP, Nandhra HS. Early intervention in psychosis: A retrospective analysis of clinical and social factors influencing duration of untreated psychosis. Prim Care Companion J Clin Psychiatry 2009;11:212-214. [http://dx.doi.org/10.4088/PCC.08m00705]

37. O'Callaghan E, Turner N, Renwick L, et al. First episode psychosis and the trail to secondary care: help-seeking and health-system delays. Soc Psychiatry Psychiatr Epidemiol 2010;45:381391. [http://dx.doi.org/10.1007/s00127-009-0081-x]

38. Koster A, Lajer M, Lindhardt A, Rosenbaum B. Gender differences in first episode psychosis. Soc Psychiatry Psychiatr Epidemiol 2008;43:940-946.

39. Albert N, Bertelsen M, Thorup A, et al. Predictors of recovery from psychosis: analyses of clinical and social factors associated with recovery among patients with first-episode psychosis after 5 years. Schizophr Res 2011;125:257-266. [http://dx.doi.org/10.1016/j. schres.2010.10.013]

40. Gattaz WF, Behrens S, de Vry J, Häfner H. Östradiol hemmt Dopamine-Vermittelte Verhaltensweisen bei Ratten - ein Tiermodell zur Untersuchung der Geschlechtsspezifischen unterschiede bei der Schizophrenie. Fortschr Neurol Psychiatr 1992;60:8-16. [http://dx.doi. org/10.1055/s-2007-999120]

41. Saldivia S, Vicente B, Kohn R, Rioseco P, Torres S. Use of mental health services in Chile. Psychiatric Serv 2004;55:71-76. [http://dx.doi.org/10.1176/appi.ps.55.1.71]

42. Andrade LH, Viana MC, Tófoli LF, Wang YP. Influence of psychiatric morbidity and sociodemographic determinants on use of service in a catchment area in the city of São Paulo, Brazil. Soc Psychiatry Psychiatr Epidemiol 2008;43:45-53. [http://dx.doi.org/10.1007/s00127007-0263-3]

43. Drukker M, Krabbendam L, Driessen G, van Os J. Social disadvantage and schizophrenia: a combined neighbourhood and individual-level analysis. Soc Psychiatry Psychiatr Epidemiol 2006;41:595-604. [http://dx.doi.org/10.1007/s00127-006-0081-z]

44. Kirkbride JB, Boydell J, Ploubidis GB, et al. Testing the association between the incidence of schizophrenia and social capital in an urban area. Psychological Med 2008;38:1083-1094. [http://dx.doi.org/10.1017/S0033291707002085]

45. Burns JK. Mental health services funding and development in KwaZulu-Natal Province: A tale of inequity and neglect. S Afr Med J 2010;100:662-666.

46. Kelly BD. Structural violence and schizophrenia. Soc Sci Med 2005;61:721-730. [http://dx.doi org/10.1016/j.socscimed.2004.12.020]

47. Wilkinson RG. Unhealthy Societies: the Afflictions of Inequality. London: Routledge, 1996.

48. Wilkinson RG. Income inequality, social cohesion, and health: clarifying the theory - a reply to Muntaner and Lynch. Int J Health Serv 1999;29:525-543. [http://dx.doi.org/10.2190/3QXP4N6T-N0QG-ECXP]

49. Diez-Roux AV, Link BG, Northridge ME. A multilevel analysis of income inequality and cardiovascular disease risk factors. Soc Sci Med 2000;50:673-687. [http://dx.doi.org/10.1016/ S0277-9536(99)00320-2]

50. Kahn RS, Wise PH, Kennedy BP, Kawachi I. State income inequality, household income, and maternal mental and physical health: cross sectional national survey. BMJ 2000;321:13111315. [http://dx.doi.org/10.1136/bmj.321.7272.1311]

51. Weich S, Lewis G, Jenkins SP. Income inequality and the prevalence of common mental disorders in Britain. Br J Psychiatry 2001;178:222-227. [http://dx.doi.org/10.1192/ bjp.178.3.222]

52. Kuznet S. Economic growth and income inequality. Am Econ Rev 1955;45:1-28. 